\title{
Polyclonal Vaccine
}

National Cancer Institute

\section{Source}

National Cancer Institute. Polyclonal Vaccine. NCI Thesaurus. Code C2728.

A class of vaccines consisting of multiple antigens conjug ated an immunostimulant, keyhole limpet hemocyanin (KLH), QS21 or gp-100. (NCI) 